\title{
Endoscopic ultrasound-guided gastrojejunostomy using a 2-cm lumen-apposing metal stent to treat benign afferent loop syndrome
}

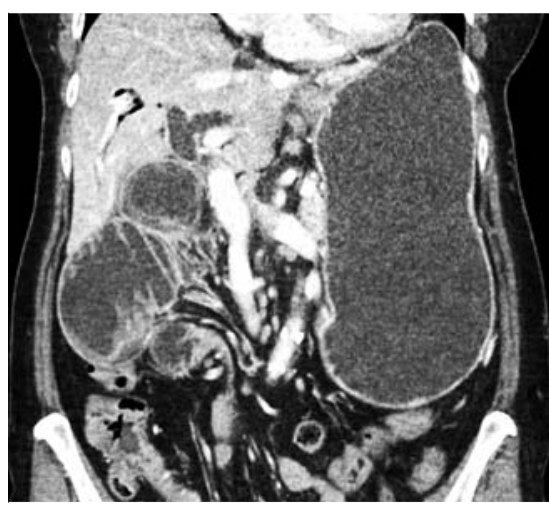

Fig. 1 Computed tomography abdomen showing afferent loop obstruction.

Afferent loop obstruction is a complication of pancreaticoduodenectomy [1]. Traditionally, afferent loop obstruction is managed by surgical or percutaneous methods. We report on a case of afferent loop obstruction treated by endoscopic ultrasound (EUS)-guided gastrojejunostomy ( $\triangleright$ Video 1 ).

A 67-year-old woman with a history of ampullary cancer treated with Whipple procedure 16 months previously presented with abdominal pain, vomiting, and weight loss. Her lipase level was elevated. Abdominal computed tomography (CT) showed a distended stomach, and dilated
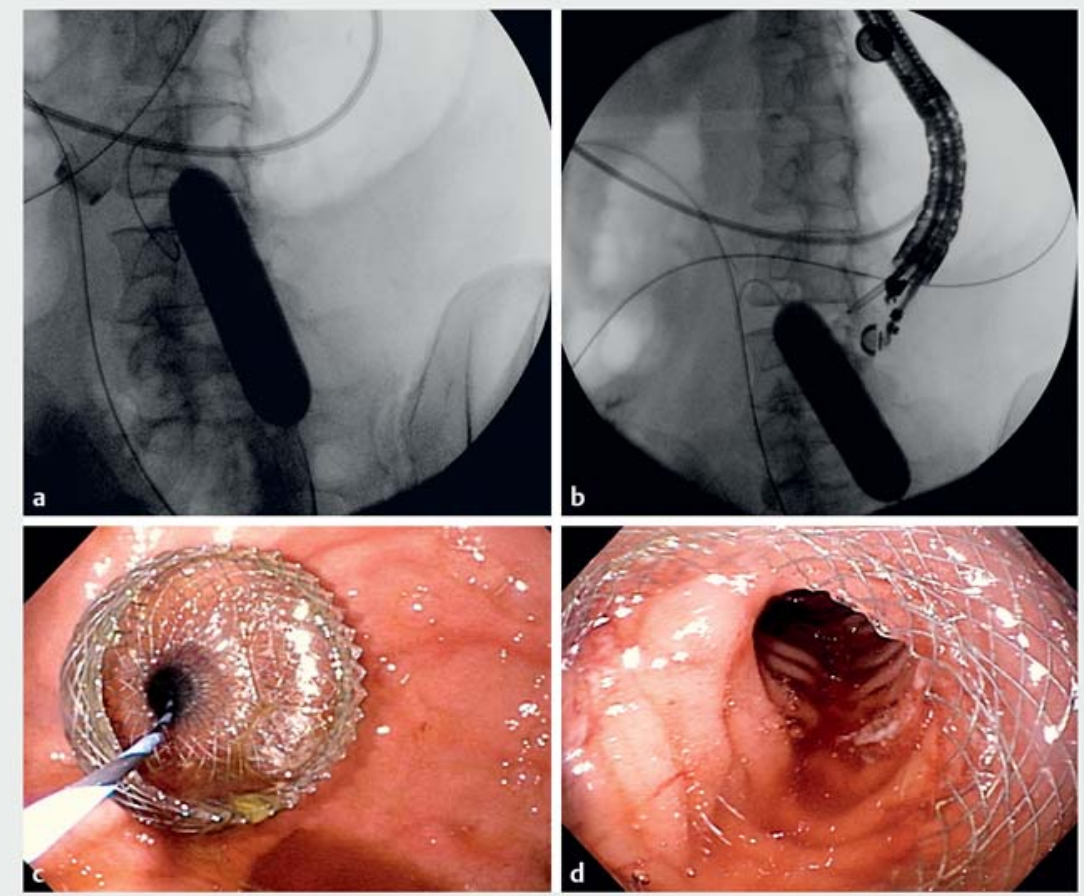

Fig. 2 Placement of the lumen-apposing metal stent (LAMS). a Fluoroscopic view of the CRE balloon (Boston Scientific, Marlborough, Massachusetts, USA), which was positioned using an overtube. $\mathbf{b}$ Fluoroscopic view showing the LAMS access catheter tip in relation to the CRE balloon. $c$ Endoscopic view of the deployed proximal flange of the LAMS.d Endoscopic view of the gastrojejunal anastomosis after stent placement. afferent limb and biliary tree ( $\triangleright$ Fig. 1 ). Upper endoscopy showed benign narrowing/angulation at the entrance to the efferent limb; the endoscope could not traverse the narrowing. A diagnosis of benign afferent loop syndrome was made. Surgical, percutaneous, and endoscopic options were discussed with the patient, and she elected to proceed with endoscopic treatment.

An overtube was mounted onto an endoscope. A guidewire was advanced to the efferent limb and the endoscope was removed. A CRE balloon catheter (Boston Scientific, Marlborough, Massachusetts, USA) was advanced over the wire and inside the overtube under fluoroscopy. The CRE balloon was positioned in the efferent jejunal loop past the narrowing and opposing the stomach silhouette. The balloon was inflated ( $>$ Fig. 2 a). The overtube was removed. An echoendoscope with a 2-cm hot AXIOS stent (Boston Scientific) was advanced to the stomach opposing the balloon ( $\mathbf{F i g} \mathbf{2} \mathbf{b}$ ). The AXIOS system catheter was advanced using electrocautery inside the balloon causing balloon rupture. The wire was advanced to the jejunum. The distal flange was deployed, followed by the proximal flange ( $\triangleright$ Fig. 2c). The LAMS was dilated up to 2 $\mathrm{cm}$ using a CRE balloon ( $\triangleright$ Fig. $\mathbf{2} \mathbf{d}$ ).

No complications occurred. CT showed decompression of the stomach and the afferent limb (> Fig.3). The patient tolerated a soft diet.

In conclusion, EUS-guided gastrojejunostomy is an alternative treatment to surgery in the management of afferent loop syndrome, particularly in patients who are poor candidates for surgery [2 -4].

Endoscopy_UCTN_Code_TTT_1AS_2AG 


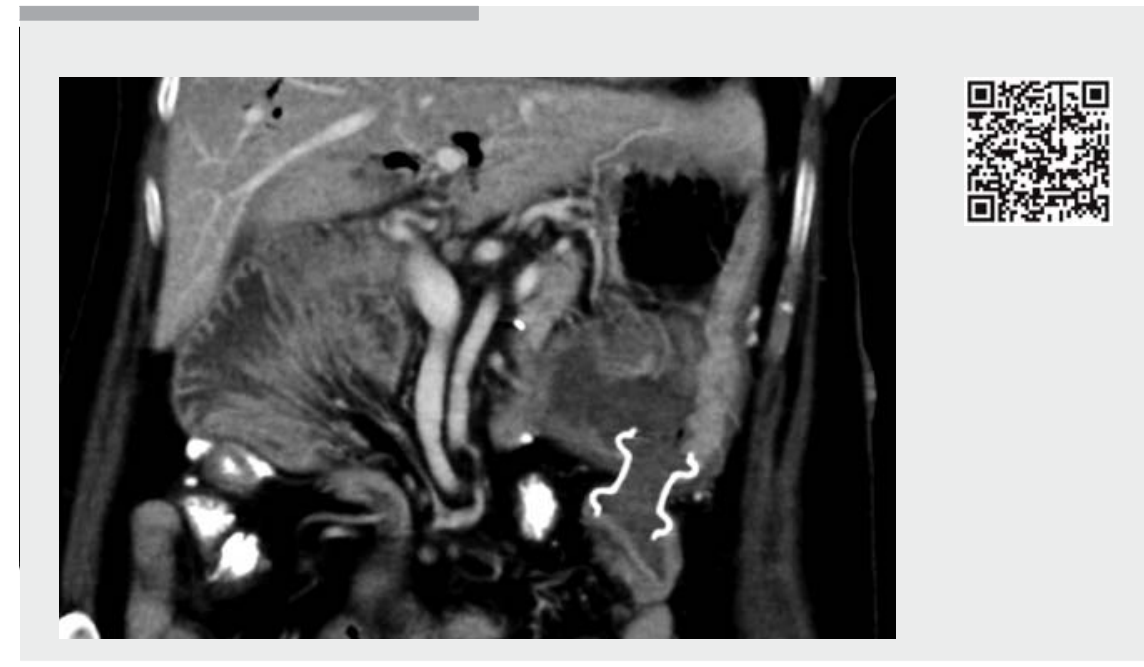

Video 1 Endoscopic ultrasound-guided gastrojejunostomy for treatment of benign afferent limb syndrome using a 2-cm diameter lumen-apposing metal stent.

\section{Competing interests}

None

The authors

Michael Lajin', Marc F. Catalano ${ }^{2}$, Naser M. Khan ${ }^{3}$, Issam Lajin ${ }^{1}$

1 Gastroenterology/Internal Medicine, SHARP Grossmont Hospital, San Diego, California, United States

2 Internal Medicine, Memorial Hermann Texas Medical Center, Houston, Texas, United States

3 Internal Medicine, DuPage Medical Group, Downers Grove, Illinois, United States

\section{Corresponding author}

\section{Michael Lajin, MD}

Gastroenterology/Internal Medicine, SHARP Grossmont Hospital, 8860 Center Drive, Suite 330, La Mesa, California 91942,

United States

Fax: +1-619-460-5148

mlajin@yahoo.com

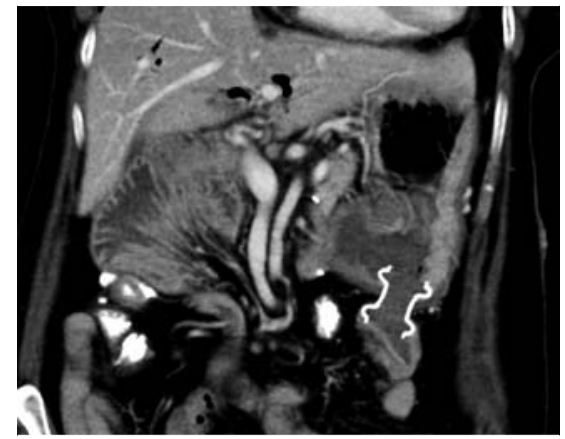

- Fig. 3 Postoperative computed tomography of the abdomen showing decompression of the afferent loop.

Bibliography

DOI https://doi.org/10.1055/a-0875-3594

Published online: 12.4 .2019

Endoscopy 2019; 51: 695-696

(c) Georg Thieme Verlag KG

Stuttgart · New York

ISSN 0013-726X 302

[2] Ikeuchi N, Itoi T, Tsuchiya T et al. One-step EUS-guided gastrojejunostomy with use of lumen-apposing metal stent for afferent loop syndrome treatment. Gastrointest Endosc 2015; 82: 166

[3] Rodrigues-Pinto E, Grimm IS, Baron TH. Efficacy of endoscopically created bypass anastomosis in treatment of afferent limb syndrome: a single-center study. Clin Gastroenterol Hepatol 2016; 14: 633-637

[4] Krafft MR, Poushanchi B, Anaka I et al. EUSguided gastrojejunostomy with an esophageal fully covered self-expanding metal stent for the management of benign afferent loop obstruction. VideoGIE 2018; 3 : $213-216$

\section{ENDOSCOPY E-VIDEOS}

https://eref.thieme.de/e-videos

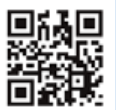

Endoscopy E-Videos is a free access online section, reporting on interesting cases and new

techniques in gastroenterological endoscopy. All papers include a high quality video and all contributions are freely accessible online.

This section has its own submission website at

https://mc.manuscriptcentral.com/e-videos 